\title{
Testosterone increases analgesia, anxiolysis, and cognitive performance of male rats
}

\author{
CHERYL A. FRYE and ANGELA M. SELIGA \\ State University of New York, Albany, New York
}

\begin{abstract}
Preliminary evidence suggests that testosterone ( $\mathrm{T}$ ) may have anxiety-reducing and cognitive-enhancing properties in animals and people. Performance in a number of affective and cognitive behavioral tasks was examined in intact, T-depleted, and T-depleted and T-replaced male rats. Rats that were gonadally intact $(n=33)$, gonadectomized (GDX; $n=30)$, or GDX with silastic capsules of T implanted $(n=28)$ were tested through a battery of affective tasks (horizontal crossing, open field, elevated plus-maze, emergence, holeboard, social interaction, tailflick, pawlick, and defensive burying) and in the inhibitory avoidance task for cognitive performance. An additional 6 rats per group had plasma androgen concentrations measured and were determined to be physiological for intact rats, supraphysiological for Timplanted rats, and near the nadir for GDX rats. Testosterone implants produced analgesia as shown by the increased tailflick latencies of the GDX rats with silastic capsules of T implanted, relative to intact or GDX rats. Testosterone also produced anxiolysis. Intact rats spent more time interacting with a conspecific and less time burying an electrified prod than did the GDX or T-implanted rats. Intact rats or GDX rats with $\mathrm{T}$ implants also spent more time on the open arms of the elevated plus-maze than did GDX rats. Testosterone also enhanced cognitive performance in the inhibitory avoidance task. Intact rats had longer crossover latenciesin the inhibitory avoidance task relative to GDX rats; GDX rats with $\mathrm{T}$ implants had longer crossover latencies relative to GDX or intact rats. Together, these data demonstrate that endogenous $\mathrm{T}$ or administration of $\mathrm{T}$ produced analgesia and enhanced affect and cognitive performance of adult male rats.
\end{abstract}

There are modest sex differences in anxiety and cognitive behaviors of people and animals. Women tend to be more anxious than men when presented with stressful stimuli (Bradley \& Wygant, 1998; Johnson, 1997; McCleary \& Zucker, 1991). Men and women also differ in their cognitive behaviors, especially in spatial ability, with males typically performing better than females (Astur, Ortiz, \& Sutherland, 1998; Gallagher et al., 2000; Linn \& Petersen, 1985; McGee, 1979). There are also sex differences in rodents' affective and cognitive behaviors. Some studies have shown that female mice spend less time on the open arms of the elevated plus-maze than do male mice (Frick, Burlingame, Arters, \& Berger-Sweeney, 2000) and female rats spend less time investigating conspecifics than do male rats (Johnston \& File, 1991). Several studies have shown that males perform better than females in mazes (Beatty, 1984; Dawson, 1972; Frye, 1995; Gaulin \& Fitzgerald, 1989; Stewart, Skvarenina, \& Pottier, 1975; Williams \& Meck, 1991). These sex differences in affective and cognitive behaviors may be in part due to or-

This research was supported by grants from the National Science Foundation (98-96263). We appreciate the assistance of Madeline Rhodes, Alicia Walf, Zoe Orecki, and Shannon Jeddi in the implementation of the studies and in the preparation of the manuscript. Correspondence should be addressed to C. A. Frye, Department of Psychology, State University of New York, 1400 Washington Avenue, Albany, NY 12222 (e-mail: cafrye@ cnsunix.albany.edu). ganizational effects of hormones on behavior (Isgor \& Sengelaub, 1998; Williams, Barnett, \& Meck, 1991).

These sex differences may also be influenced by activational effects of androgens on affective and cognitive behaviors. Female rats in proestrus, which have increased androgen levels relative to female rats in diestrus, show more anxiolytic behavior than do diestrous or male rats (Frye, Petralia, \& Rhodes, 2000). Some findings also support the notion that performance on some cognitive tasks may be improved during proestrus relative to diestrus (Warren \& Juraska, 1997). Androgen administration can increase analgesia and anxiolysis in male rats (Bitran, Kellogg, \& Hilvers, 1993; Forman, Tingle, Estilow, \& Cater, 1989) and in female rats (Molina, Bedran-de-Castro, \& Bedran-deCastro, 1994; Romero, Cooper, Komisaruk, \& Bodnar, 1988). Androgens may also improve cognitive performance of male mice (Flood, Farr, Kaiser, La Regina, \& Morley, 1995; Flood, Morley, \& Roberts, 1992) and of male (Kritzer, McLaughlin, Smirlis, \& Robinson, 2001; VazquezPereyra, Rivas-Arancibia, Loaeza-Del Castillo, \& Schneider-Rivas, 1995) and female (Frye \& Lacey, 2001) rats.

There is also evidence that androgens may affect anxiety and cognitive behaviors in people. Low levels of testosterone (T) in women are correlated with decreased motivation, chronic fatigue, and a decreased sense of well-being relative to that reported by women with normal $\mathrm{T}$ levels (Davis, 2001). Men with low levels of T indicate they tend to be more irritable, be more sleep deprived, have poorer memory, and be more anxious than men with normal $\mathrm{T}$ 
levels (Sternbach, 1998). Elderly men with low T serum levels can experience andropause, which is characterized by decreased libido, stamina, and cognitive functioning (J. E. Morley, 2000). T replacement therapy may ameliorate some of these deficits experienced by andropausal men (Lund, Bever-Stille, \& Perry, 1999; J. E. Morley, Kaiser, Sih, Hajjar, \& Perry, 1997). T may benefit healthy adults, especially elderly adults, who typically have lower $\mathrm{T}$ levels. T administration may improve spatial and working memory in healthy adult men (Christiansen \& Knussmann, 1987; Janowsky, Chavez, \& Orwoll, 2000; Janowsky, Oviatt, \& Orwoll, 1994; Silverman, Kastuk, Choi, \& Phillips, 1999) and may improve object-location memory in healthy adult women (Postma et al., 2000).

Due to the potential benefits of $\mathrm{T}$ on affect and cognition, it is important to begin to understand the nature of T's effects in controlled experiments. The purpose of this experiment was to test the hypothesis that androgens will enhance analgesia, anxiolysis, and cognitive performance in a number of behavioral assays of intact or T-replaced male rats relative to $\mathrm{T}$-depleted rats.

\section{METHOD}

These methods were preapproved by the Institutional Animal Care and Use Committee at SUNY, Albany.

\section{Animals and Housing}

Male Long-Evans rats $(N=109)$, approximately 55 days of age, were obtained from Taconic Farms (Germantown, NY). Rats were group housed (4 per cage) in polycarbonate cages $(45 \times 24 \times$ $21 \mathrm{~cm})$ in a temperature- and humidity-controlled room $\left(21 \pm 1^{\circ} \mathrm{C}\right)$ in the laboratory animal care facility. The rats were maintained on a 12/12-h reversed light cycle (lights off 8:00 a.m.) with access to $\mathrm{Pu}-$ rina Rat Chow and tap water in their home cages.

\section{Surgery}

Rats were randomly assigned to one of three groups: intact, gonadectomized (GDX), or GDX with T implants. Some rats $(n=70)$ were anesthetized with rompun $(60 \mathrm{mg} / \mathrm{kg})$ and Ketaset $(80 \mathrm{mg} / \mathrm{kg})$ for GDX. Of these GDX rats, some $(n=34)$ received a single silastic implant (1.57-mm inner diameter, 3.18-mm outer diameter) following the GDX procedure. The implants contained crystalline $\mathrm{T}$ (Sigma, St. Louis; $10 \mathrm{~mm} /$ animal) to provide a sustained amount of $\mathrm{T}$ throughout all behavioral testing.

\section{Behavioral Testing}

Anxiolytic behavior in rodents can be assessed using a battery of tests, which are used collectively to examine factors that influence anxiety (Johnston \& File, 1991; Pellow, Chopin, File, \& Briley, 1985). One of three experimenters (interrater reliability was greater than $95 \%$ ) tested up to 12 rats daily, each for approximately $60 \mathrm{~min}$, in one of two brightly lit rooms adjacent to the animal housing facility. The battery of tests was administered to each rat individually in the same order without any rest periods due to one or more of these tasks possibly influencing behavior on subsequent tasks. Any carryover effects from previous tasks would therefore be uniform across all rats. In one room, rats were exposed to horizontal crossing, open field, elevated plus-maze, emergence, and holeboard. Immediately following completion of holeboard in the first room, rats were tested in the social interaction, tailflick, pawlick, and defensive burying tasks in the second room. Apparatus for all of the tasks were not moved from one room to the other for the entire test period. At least $24 \mathrm{~h}$ after defensive burying, rats were habituated to inhibitory avoidance to as- sess spatial/nonmotor dependent memory. Twenty-four hours after training, rats were tested in inhibitory avoidance. Each test is described below.

\section{Horizontal Crossing}

The horizontal crossing has previously been used to effectively assess motor behavior (Brudzynski \& Krol, 1997; Frye et al., 2000). Rats were placed in a brightly lit $39 \times 39 \times 30 \mathrm{~cm}$ Digiscan Optical Animal Activity Monitor (Accuscan Instruments Inc., Columbus, $\mathrm{OH}$ ), and the total number of beam breaks that occurred in $5 \mathrm{~min}$ was mechanically recorded.

\section{Open Field}

The open field described by Frye et al. (2000) and Pellow and File (1986) was utilized to assess anxiety and motor behavior. The open field box $(76 \times 57 \times 35 \mathrm{~cm})$ used has a 48 -square grid floor $(6 \times 8$ squares, $9.5 \mathrm{~cm} / \mathrm{side})$ and an overhead light illuminating the central squares (all but the 24 perimeter squares were considered central). As described by McCarthy, Felzenberg, Robbins, Pfaff, and SchwartzGiblin (1995), rats were placed in the bottom left corner of the open field and observed for 5 min while an experimenter recorded the number of central and peripheral squares the rat entered.

\section{Tailflick}

The tailflick paradigm described by D'Amour and Smith (1941) and methods described by Frye and Duncan $(1994,1995)$ were utilized to assess nociception. Rats were handled, covered with a towel, placed on a platform of the tailflick apparatus (San Diego Instruments, San Diego), and held in place while their tails were smoothed above the radiant heat source. The mean latency of three tailflick trials was used as an index of nociception with a maximum latency of $10 \mathrm{sec}$.

\section{Social Interaction}

Social interaction was also utilized to assess anxiety and exploratory behavior (Cheeta, Irvine, Kenny, \& File, 2001; Frye et al., 2000). The social interaction test described by Ge, Barnes, Costall, and Naylor (1997) was conducted in an open field apparatus $(60 \times$ $60 \times 35 \mathrm{~cm})$ similar to that used for the holeboard test. A stimulus male rat was placed in one corner of the open field, the experimental male was placed in the opposite corner, and the rats were left undisturbed for $10 \mathrm{~min}$. An experimenter recorded the total duration of time (in seconds) that the experimental male engaged the stimulus male in crawling over and under partner, sniffing partner, following with contact, investigating partner's genitals, tumbling, boxing, and grooming. Stimulus rats were conspecifics that were randomly selected from a pool of rats that were not behaviorally tested in this study.

\section{Defensive Burying}

The defensive burying test can accurately assess anxiety in response to a shock stimulus (Frye et al., 2000; Gallo \& Smith, 1993; Treit, 1985; Treit, Pinel, \& Fibiger, 1981). The test apparatus $(26.0 \times$ $21.2 \times 24.7 \mathrm{~cm}$ ) was constructed of clear Plexiglas. In the right rear corner of the apparatus, an electrified probe $(2.5 \mathrm{~cm}$ in diameter and $10.0 \mathrm{~cm}$ in height) was placed $3.0 \mathrm{~cm}$ from the back wall and $2.5 \mathrm{~cm}$ from the right wall. Wood chip bedding was added $(5.0-\mathrm{cm}$ deep from the bottom of the chamber), and the probe extended $4.5 \mathrm{~cm}$ above the bedding. The probe was wrapped by two wires that were connected to a shock source (Lafayette Model A615B, Lafayette, IN) set to deliver $6.66 \mathrm{~mA}$ of unscrambled shock when the animal placed both forepaws on the pedestal. Once the animal received the shock, the experimenter terminated the shock and recorded the duration of burying behavior manifest in response to the shock stimulus for a 15-min period.

\section{Pawlick}

The pawlick test, described by Bardo and Valone (1994), Frye et al. (2000), and Smythe, McCormick, Rochford, and Meaney (1994), was also utilized to assess nociception and anxiety. The pawlick apparatus consisted of a slide-warming tray (Fisher Scientific, Swanee, 
GA; Model 77) heated to $53^{\circ} \mathrm{C}$. Rats were confined to the tray by placing a clear, floorless, plastic chamber $(28.5 \times 17.5 \times 12.5 \mathrm{~cm})$ on top of the hotplate. Rats were placed in the chamber on the hotplate, and the latency to lick the hindpaw was recorded (maximum latency $180 \mathrm{sec})$.

\section{Emergence Test}

The emergence test has previously been used to effectively assess anxiety and exploratory behavior (Frye et al., 2000; Holson, Ali, Scallet, Slikker, \& Paule, 1989; K. C. Morley \& McGregor, 2000). Rats were placed in a closed opaque cylinder $(21 \times 7 \times 7 \mathrm{~cm})$ that was set in an open field and secured to prevent rolling. The lid was removed and the latency for the rat to emerge completely (all four paws) from the cylinder into the open field was recorded (maximum latency $15 \mathrm{~min}$ ).

\section{Elevated Plus-Maze}

The elevated plus-maze paradigm has also been used effectively to assess anxiety and exploratory behavior (Frye et al., 2000; Pellow et al., 1985). The elevated plus-maze consisted of four arms, $49-\mathrm{cm}$ long and $10-\mathrm{cm}$ wide, elevated $50-\mathrm{cm}$ off the ground. Two arms were enclosed by walls $30-\mathrm{cm}$ high, and the other two arms were exposed. As described by Pellow and File (1986) and Dunn, Copeland, Reed, and Frye (1998), rats were placed at the junction of the open and closed arms of the maze and were observed for $5 \mathrm{~min}$. An experimenter recorded the number of entries and the amount of time spent on the open and closed arms. Rats were considered to be in either the closed or the open arms of the maze, and open arm time was recorded only when the rat had all four paws on the open arm of the elevated plus-maze.

\section{Holeboard}

The holeboard task was another measure utilized to assess exploratory and motor behavior (File, Pellow, \& Braestrup, 1985; Frye et al., 2000; Zangrossi \& File, 1992). The holeboard was an open field $(60 \times 60 \times 35 \mathrm{~cm})$ divided into nine equal squares. At the four intersecting grid lines were equally spaced holes (each $3.8-\mathrm{cm}$ diameter). As described by Zangrossi and File, rats were placed in the box and the incidence of head dips into the holes and total number of squares entered were recorded by an experimenter for a period of $5 \mathrm{~min}$.

\section{Inhibitory Avoidance}

The step-through inhibitory avoidance task was utilized to assess spatial/nonmotor dependent memory (Frye \& McCormick, 2000; O'Connell, Earley, \& Leonard, 1994; Venault et al., 1986). A twocompartment $(24 \times 18 \times 19 \mathrm{~cm}$ each), stainless steel box similar to that described by Venault et al. was separated in half by a guillotine door. One chamber was brightly lit from above and painted white. The other chamber was painted black and covered to block out light.

Habituation and training (Day 1). Each rat was first placed in the white chamber (head facing the door with the door down) and allowed to explore the white chamber for $2 \mathrm{~min}$. After habituating a group of animals (no longer than $.5 \mathrm{~h}$ after habituating the 1st animal), the 1st rat that was habituated was placed in the white chamber (head facing the door with the door down) for $1 \mathrm{~min}$. The door was lifted and the latency for the rat to cross over to the dark chamber was recorded (maximum latency $20 \mathrm{~min}$ ). The door was closed behind them and rats then received a mild shock $(0.25 \mathrm{~mA}, 2-\mathrm{sec}$ duration). If rats did not cross over during training, they were not tested on Day $2(n=8)$.

Testing (Day 2). Twenty-four h later, rats were placed in the white chamber for $1 \mathrm{~min}$ (head facing the door with the door down). The door was lifted and the latency to enter the dark chamber was recorded (maximum latency $5 \mathrm{~min}$ ).

\section{Androgen Measurement}

Eighteen rats ( $n=6$ per group), which were not behaviorally tested, were rapidly decapitated and trunk blood was collected at the time analogous to behavioral testing. Following centrifugation and storage at $-70^{\circ} \mathrm{C}$, plasma from samples were measured for concentrations of T, its $5 \alpha$-reduced metabolite dihydrotestosterone (DHT), and its $3 \alpha$-hydroxysteroid dehydrogenase metabolite, $5 \alpha$ androstane-3 $\alpha, 17 \beta$-diol ( $3 \alpha$-Diol). Briefly, androgens were extracted from plasma with diethyl ether, samples were reconstituted in phosphate assay buffer ( $\mathrm{ph}=7.4$ ), equilibrated, and analyzed by enzyme-linked immunosorbent assay (T: Oxford Biomedical Research EA78) or radioimmunoassay (DHT, Endocrine Sciences, DT3-351, 1:20,000 and 3 $\alpha$-Diol, Southwestern Foundation for Biomedical Research, X-144, 1:20,000; Frye, McCormick, Coopersmith, \& Erskine, 1996; Frye, Van Keuren, Rao, \& Erskine, 1996b) to determine the circulating concentrations of androgens among groups.

\section{Statistical Analyses}

Multiple one-way analyses of variance (ANOVAs) were used to examine the differences between the groups on the various behavioral and endocrine measures examined. Where appropriate, ANOVAs were followed by Fisher's post hoc tests to determine differences among the groups. Alpha level for the determination of statistical significance was $p \leq .05$.

\section{RESULTS}

\section{Horizontal Crossing}

Intact rats made a significantly $[F(2,88)=3.124, p=$ $.04]$ greater total number of beam breaks in horizontal crossings relative to the GDX rats and the GDX rats with T implants (Figure 1, top panel). There were no significant differences between the GDX rats and the T-replaced rats in the total number of beam breaks.

\section{Open Field}

Intact rats tended to enter $[F(2,88)=2.807, p=.06]$ more total squares in the open field relative to T-replaced rats (Figure 1, bottom left panel). There were no significant differences between GDX rats and the intact rats or between GDX rats and T-replaced rats in the total number of squares entered.

Intact rats entered significantly $[F(2,88)=4.067, p=$ $.02]$ more outer squares in the open field relative to $\mathrm{T}$ replaced rats (Figure 1, bottom right panel). There was a tendency for GDX rats to enter more outer squares in the open field relative to T-replaced rats, but there were no significant differences between intact rats and GDX rats.

There were no significant differences between the groups in the number of central entries in the open field. The number of central entries for each group were as follows: intact rats $(7.6 \pm 1.2)$, GDX rats $(5.8 \pm 1.1)$, and T-replaced rats $(5.8 \pm 1.1)$.

\section{Tailflick}

T-replaced rats had significantly $[F(2,88)=4.761, p=$ $.01]$ increased tailflick latencies relative to the intact rats and the GDX rats (Figure 2). There were no significant differences between intact rats and GDX rats in their tailflick latencies.

\section{Social Interaction}

Intact rats spent a significantly greater $[F(2,88)=9.502$, $p=.0002]$ amount of time in contact with a conspecific in genital investigation, sniffing, crawling over and under, 

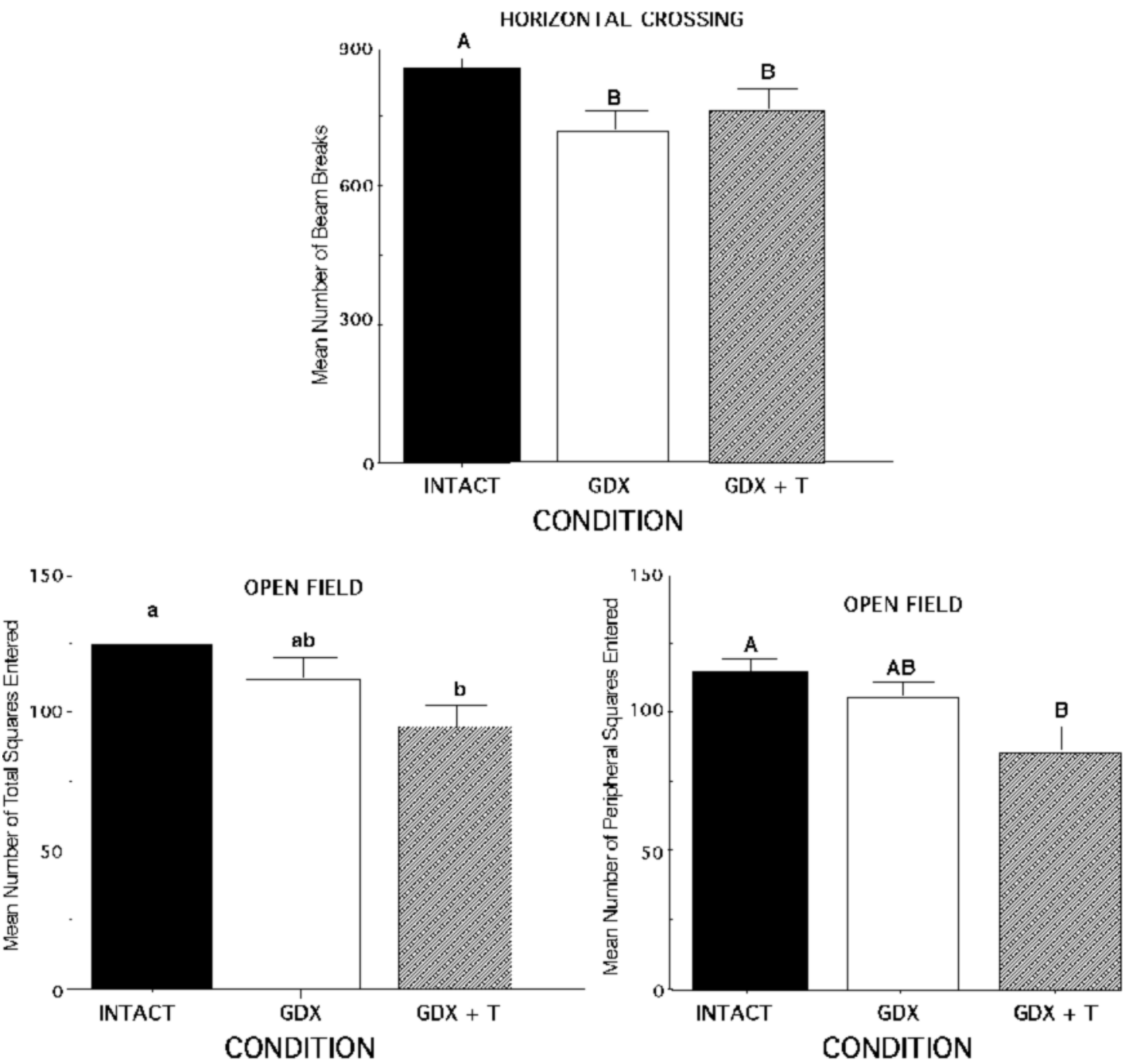

Figure 1. The top panel represents the mean number of beam breaks $( \pm S E M)$ in the horizontal crossing task of intact (black bar), GDX (white bar), and GDX + T rats (gray bar). Bars with different letters are significantly different from each other $(p<.05)$. The bottom left panel represents the mean number of total squares entered $( \pm S E M)$ in the open field of intact $(b l a c k$ bar), GDX (white bar), and GDX + T rats (gray bar). Bars with different letters represent a tendency to be different from each other $(p=.06)$. The bottom right panel represents the mean number of peripheral squares entered $( \pm S E M)$ in the open field of intact (black bar), GDX (white bar), and GDX + T rats (gray bar). Bars with different letters are significantly different from each other $(p<.05)$.

tumbling, boxing, and grooming interaction time relative to the GDX rats and the T-replaced rats (Figure 3).

\section{Defensive Burying}

Intact rats spent significantly $[F(2,88)=3.139, p=.04]$ less time burying the electrified probe relative to the GDX rats or GDX rats with T implants (Figure 4).

\section{Pawlick}

There were no significant differences between the groups in the latencies to lick the hindpaw. The pawlick latencies for each group were as follows: intact rats (125.2 \pm 9.5), GDX rats (115.7 \pm 8.5$)$, and T-replaced rats (137.9 \pm $9.0)$.

\section{Emergence}

There were no significant differences between the groups in the latencies to emerge completely from the cylinder. The mean emergence latencies for each group were as follows: intact rats $(468.4 \pm 64.2)$, GDX rats $(471.0 \pm 69.4)$, and T-replaced rats $(430.0 \pm 69.3)$.

\section{Elevated Plus-Maze}

GDX rats spent significantly $[F(2,88)=5.170, p=$ .007] less time on the open arms of the elevated plusmaze relative to intact rats or T-replaced rats (Figure 5). There were no significant differences between intact rats and T-replaced rats in the amount of time spent on the open arms. 


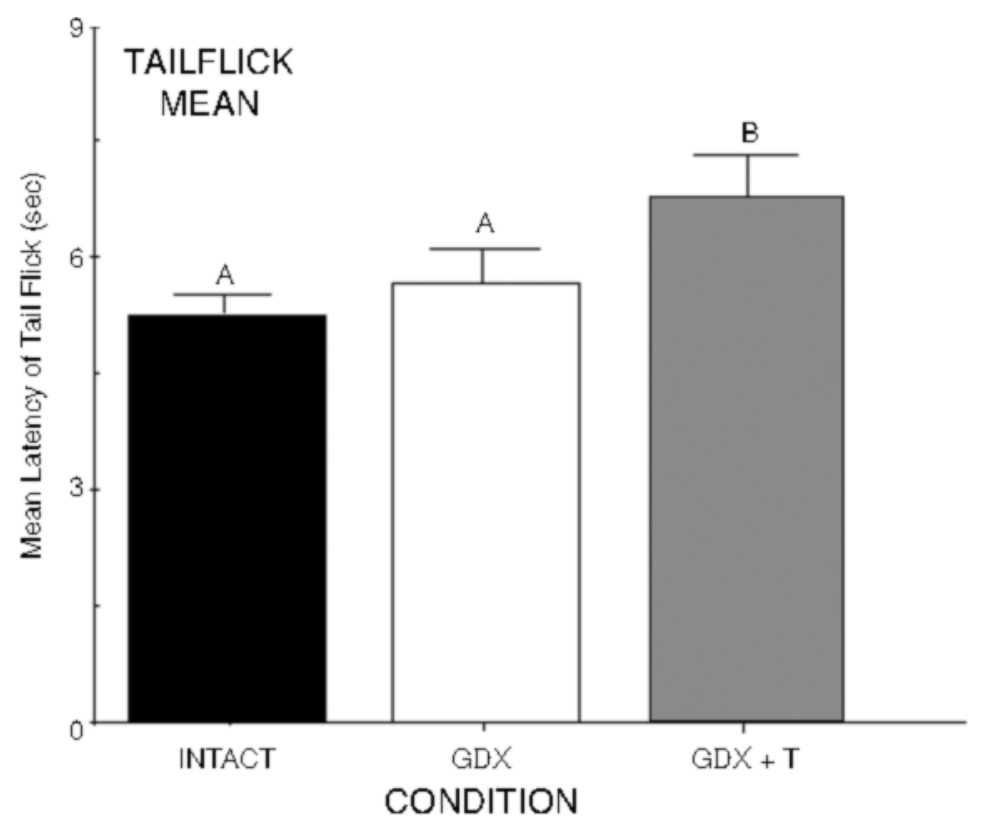

Figure 2. Mean tailflick latencies ( $\pm S E M$ ) of intact (black bar), GDX (white bar), and GDX + T rats (gray bar). Bars with different letters are significantly different from each other $(p<.05)$.

\section{Holeboard}

There were no significant differences between groups in the total number of squares entered or the number of head dips. The mean numbers of squares entered for each group were as follows: intact rats $(29.3 \pm 3.2)$, GDX rats $(25.5 \pm$ $2.8)$, and T-replaced rats $(24.4 \pm 2.8)$. The mean numbers of head dips for each group were as follows: intact rats $(1.06 \pm 0.04)$, GDX rats $(0.4 \pm 0.2)$, and T-replaced rats $(0.3 \pm 0.1)$.

\section{Inhibitory Avoidance}

Intact rats had significantly $[F(2,80)=8.078, p=.0006]$ longer latencies to cross over to the dark chamber relative to the GDX rats. T-replaced rats also had significantly longer latencies to cross over to the dark chamber relative to intact and GDX rats (Figure 6).

\section{Androgen Concentrations}

$\mathrm{T}[F(2,15)=90.139, p=.0001]$, DHT $[F(2,15)=$ $57.48, p=0.0001]$, and $3 \alpha-\operatorname{Diol}[F(2,15)=39.93, p=$ $.0001]$ concentrations were significantly different across groups (Table 1). Androgen concentrations were supraphysiological and significantly increased in T-replaced rats relative to intact and GDX rats. Intact rats had androgen concentrations that were physiological and congruous with those previously reported in the literature. Androgen concentrations were significantly greater for intact rats than GDX rats, which had androgen concentrations near the nadir. $T$ concentrations in intact adult male rats range from approximately 2.0 to $5.0 \mathrm{ng} / \mathrm{ml}$ (Gupta, Rager, Zarzycki, \& Eichner, 1975; Moger, 1977). DHT concentra- tions between $0.1 \mathrm{ng} / \mathrm{ml}$ and $1.5 \mathrm{ng} / \mathrm{ml}$ have been reported for intact adult male rats (Gupta et al., 1975; Moger, 1977). Concentrations of $3 \alpha$-Diol for intact adult male rats typically range from $1.0 \mathrm{ng} / \mathrm{ml}$ to $2.0 \mathrm{ng} / \mathrm{ml}$ (Moger, 1977).

\section{DISCUSSION}

The results of this experiment are consistent with our hypothesis that androgensincrease analgesia, anxiolysis, and cognitive performance. $T$ administration produced analgesia, as demonstrated by the increased tailflick latencies in the rats with $\mathrm{T}$ implants relative to the intact and GDX rats without implants. Intact male rats exhibited less anxious behavior relative to the other rats, as seen by their increase in the duration of social interaction and their decrease in time spent burying an electrified probe. Both intact and T-replaced rats also exhibited less anxious behavior by spending more time on the open arms in the elevated plusmaze relative to androgen-depleted rats. Intact rats demonstrated an improvement in cognitive performance relative to androgen-depleted rats, as shown by their significantly longer crossover latencies in the inhibitory avoidance task. T-replaced rats also had longer crossover latencies in the inhibitory avoidance task relative to intact or androgendepleted rats. Together these data suggest that androgens can have analgesic, anxiolytic, and enhancing effects on cognitive performance.

The present findings provide additional support for androgens' role in reducing nociception. Previous research has shown that androgen treatment can produce analgesia in androgen-depleted male rats (Forman et al., 1989) and in 


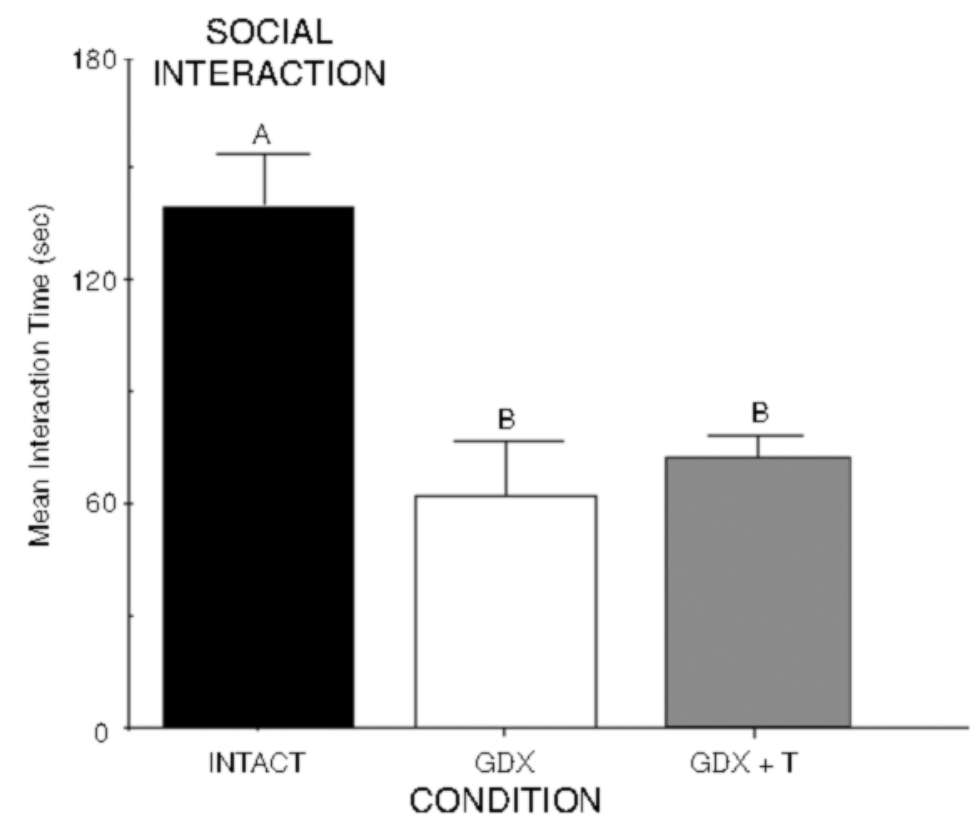

Figure 3. Mean duration of time spent interacting with conspecific in seconds ( $\pm S E M$ ) of intact (black bar), GDX (white bar), and GDX + T rats (gray bar). Bars with different letters are significantly different from each other $(p<.05)$.

female rats (Molina et al., 1994; Romero et al., 1988) by increasing the latencies to withdraw their tails from hot water. Similarly, our findings showed that $\mathrm{T}$ administration to rats produced analgesia, as demonstrated by their increased latencies to withdraw their tails from a radiant heat source. Notably, in the pawlick task, T-replaced rats had the longest latencies to lick their hindpaw; however, there were no statistically significant differences between the T-replaced rats and the GDX or intact rats on this measure.

The present findings also provide additional support for androgens' role in reducing anxiety. Intact and T-replaced

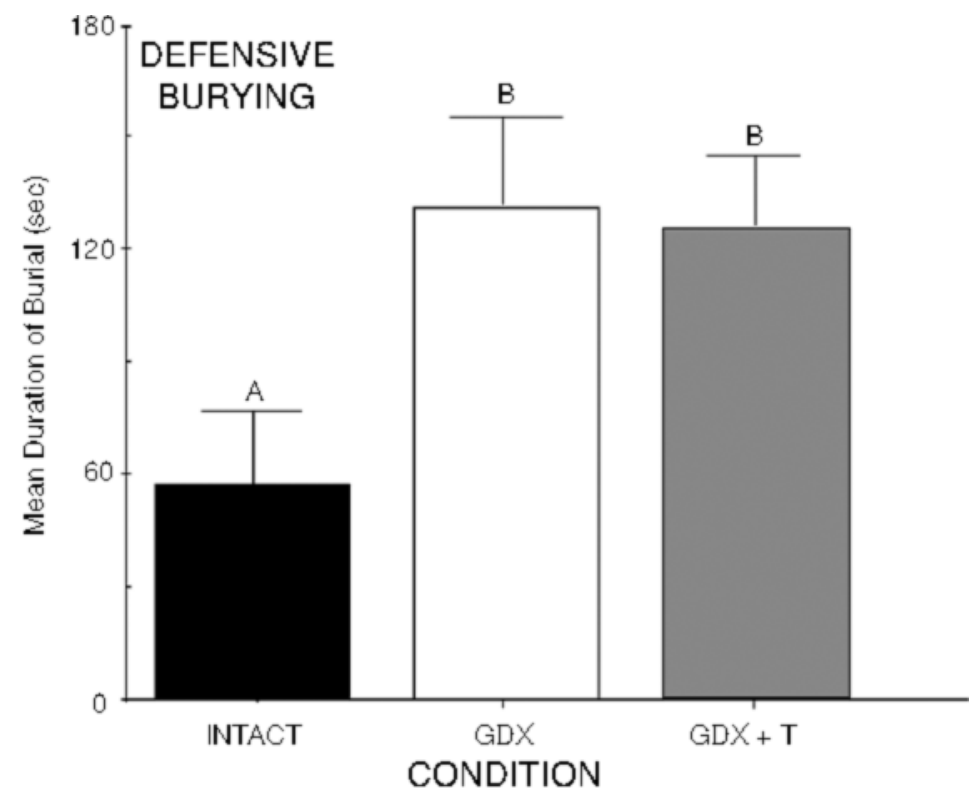

Figure 4. Mean duration of postshock burial ( \pm ) of intact (black bar), GDX (white bar), and GDX + T rats (gray bar). Bars with different letters are significantly different from each other $(p<.05)$. 


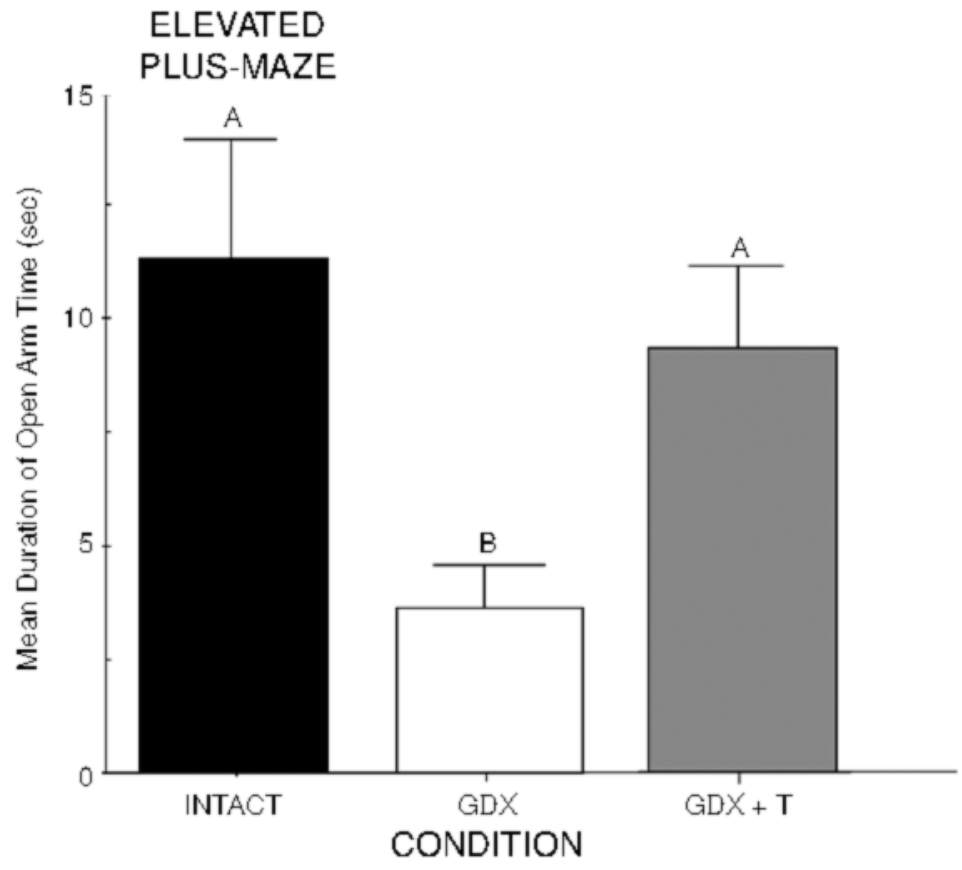

Figure 5. Mean open arm time $( \pm S E M)$ on the elevated plus-maze of intact (black bar), GDX (white bar), and GDX + T rats (gray bar). Bars with different letters are significantly different from each other $(p<.05)$.

rats in the present experiment exhibited more anxiolytic and exploratory behavior by spending more time on the open arms of the elevated plus-maze, which is consistent with other findings showing that $\mathrm{T}$ administration to male rats increased open arm exploration in the elevated plus- maze (Bitran et al., 1993). Prolonged T treatment has been shown to decrease fear responses of ewes and heifers in a battery of tests involving unfamiliar stimuli (Boissy \& Bouissou, 1994; Vandenheede \& Bouissou, 1993). T implants also produce dose-dependent, anxiolytic effects in

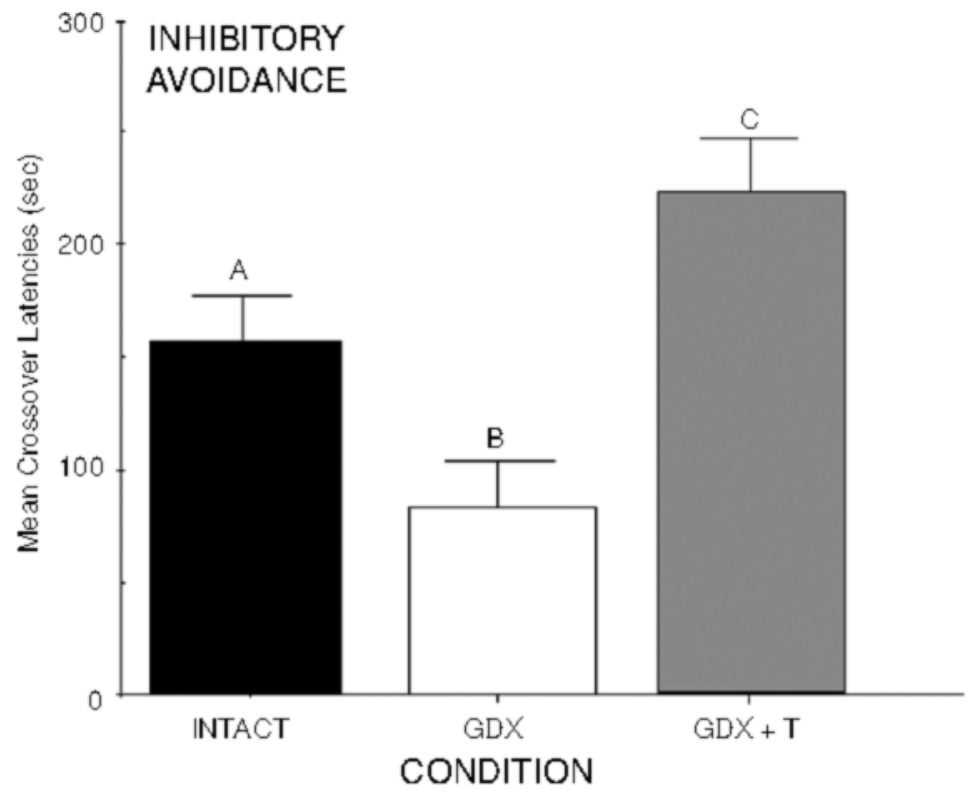

Figure 6. Mean crossover latencies $( \pm S E M)$ in inhibitory avoidance of intact (black bar), GDX (white bar), and GDX + T rats (gray bar). Bars with different letters are significantly different from each other $(p<.05)$. 
Table 1

Androgen Concentrations in Plasma of the Experimental Groups $(n=6$ Per Group)

\begin{tabular}{lccc}
\hline & \multicolumn{3}{c}{ Plasma Androgen Concentrations $(\mathrm{ng} / \mathrm{ml})$} \\
\cline { 2 - 4 } \multicolumn{1}{c}{ Group } & Testosterone & Dihydrotestosterone & $3 \alpha$-Diol \\
\hline T-replaced & $7.7 \pm 0.5^{*}$ & $2.7 \pm 0.2^{*}$ & $2.9 \pm 0.2^{*}$ \\
Intact & $3.0 \pm 0.4^{+}$ & $1.4 \pm 0.2^{+}$ & $1.5 \pm 0.3^{+}$ \\
GDX & $0.4 \pm 0.1$ & $0.1 \pm 0.1$ & $0.2 \pm 0.1$ \\
\hline
\end{tabular}

Note-*indicates testosterone, dihydrotestosterone, and $3 \alpha$-Diol concentrations were each significantly $(p<.0001)$ increased in T-replaced relative to intact and GDX groups. +indicates testosterone, dihydrotestosterone, and $3 \alpha$-Diol concentrations were each significantly $(p<.0001)$ increased in intact rats relative to GDX rats.

male rats (Gonzalez, Farabollini, Albonetti, \& Wilson, 1994). Notably in tasks other than the plus-maze, intact rats showed less fearful responses to novel stimuli than did GDX and/or T-replaced rats. For example, intact rats tended to explore more in the open field, spent more time interacting with a conspecific, and spent less time burying the shock prod than did other rats. In the holeboard task and in central entries in the open field, there was a similar pattern for the intact rats to have entered the greatest number of squares, and to make the most head dips, relative to the other groups. Although these findings are consistent with the aforementioned data, these differences were not statistically significant. Hence, there was not statistically significant evidence for androgens to reduce anxiety in all of the behavioral tasks examined, which presumably measure similar constructs. Further, there was no evidence for effects of androgens in the emergence task. Differences between the groups in performance on the various behavioral tasks of anxiety (and analgesia) may reflect sensitivity of the various measures to discriminable differences in physiological (intact rats) versus supraphysiological(T-replaced rats) or threshold (GDX rats) concentrations of androgens.

The present findings also support previous studies demonstrating that androgen treatment facilitates cognitive functioning. T replacement to mice improves learning and memory in a footshock avoidance task (Flood et al., 1995; Flood et al., 1992). T replacement to male rats improves performance in the T-maze task (Kritzer et al., 2001) and improves the short-term memory of male rats in the inhibitory avoidance task (Vazquez-Pereyra et al., 1995). $\mathrm{T}$ administration to female rats enhances cognitive performance in the Y-maze, inhibitory avoidance, and object recognition tasks (Frye \& Lacey, 2001). The present findings provide additional support for $\mathrm{T}$ improving memory, as demonstrated by the intact rats having significantly greater crossover latencies than androgen-depletedrats and T-replaced rats having significantly longer crossover latencies than androgen-depleted or intact rats. The previous and present data suggest $\mathrm{T}$ can enhance cognitive performance.

The T-administered rats in the present study showed less motor behavior in the horizontal crossing task and in the open field relative to the intact and androgen-depleted rats.
Reports of T's effects on motor behavior vary across the literature. One study showed that $\mathrm{T}$ administration to male rats did not affect open field activity (Bitran et al., 1993), whereas other studies showed that $\mathrm{T}$ concentrations were inversely related to activity in the open field, with higher T levels associated with less activity (Lambadjieva, 1998; Rodriguez, Sosa, Hernandez, \& Mas, 1984). The rats in the present study received a sustained amount of $\mathrm{T}$ from the implants, which produced supraphysiological concentrations of androgens and may have been sufficient to produce modest changes in motor behavior.

T's mechanism of action to produce analgesia, anxiolysis, and to enhance cognitive performance may be in part due to its metabolism. T is metabolized by $5 \alpha$ reductase to form DHT, which is then metabolized by $3 \alpha$-hydroxysteroid dehydrogenase to form to $3 \alpha$-Diol. T and DHT have a high affinity for intracellular androgen receptors (ARs; Cunningham, Tindall, \& Means, 1979; Verhoeven, Heyns, \& De Moor, 1975), but $3 \alpha$-Diol does not (Roselli, 1991). $3 \alpha$-Diol is a potent modulator at $\mathrm{GABA}_{\mathrm{A}}$ / benzodiazepine receptor complexes (GBRs), whereas T and DHT have only weak activity at GBRs (Frye, Duncan, Basham, \& Erskine, 1996; Frye \& Reed, 1998; Frye, Van Keuren, \& Erskine, 1996; Frye, Van Keuren, Rao, \& Erskine, 1996a, 1996b; Gee, 1988). Androgens can change GBR pharmacodynamics, as demonstrated by gonadectomy decreasing sensitivity to diazepam-induced sedation (Svensson, Soderpalm, \& Engel, 2000).

The similar effects of T, DHT, and $3 \alpha$-Diol to produce analgesia and anxiolysis or enhance cognitive performance (Frye \& Lacey, 2001) suggest that their actions may be a result of metabolism to, or production of, $3 \alpha$-Diol and subsequent actions at GBRs. In support, administration of $3 \alpha$-Diol (3.0 or $7.5 \mathrm{mg} / \mathrm{kg} \mathrm{SC}$ ) to ovariectomized (OVX) rats produces analgesia in the tailflick paradigm (Frye et al., 1996a). Androgen regimes that increase $3 \alpha$-Diol concentrations significantly increase open arm time in the elevated plus-maze (Bitran et al., 1993). Posttraining administration of systemic T, DHT, or $3 \alpha$-Diol (3.0 or $7.5 \mathrm{mg} / \mathrm{kg}$ ) to OVX rats produces increases in the percentages of correct choices in the Y-maze, latencies to crossover to the shock-associated side in the inhibitory avoidance task, and the percentage of time spent with a novel object in the object recognition task (Frye \& Lacey, 2001). Further evidence that $3 \alpha$-Diol, rather than $\mathrm{T}$ or DHT, is responsible for androgens enhancing effects on cognitive performance includes situations in which $3 \alpha-$ Diol has greater effects on cognitive performance than $T$ or DHT. $3 \alpha$-Diol, but not T or DHT $(1.0 \mathrm{mg} / \mathrm{kg})$, to adrenalectomized (ADX) male rats significantly increases latencies to crossover to the dark chamber in the inhibitory avoidance task (Frye \& McCormick, 2000). Similarly, $3 \alpha$ Diol, but not T or DHT, to male rats enhances conditioned place preference (Frye, Park, Tanaka, Rosellini, \& Svare, 2001 ) by increasing $3 \alpha$-Diol concentrations in the nucleus accumbens (Rosellini, Svare, Rhodes, \& Frye, 2001), a region of the brain that is lacking in ARs (Stumpf \& Sar, 
1976), but that has many GBRs. These findings suggest that T's effects on affective and cognitive behaviors may result in part from its metabolism to $3 \alpha$-Diol.

In addition to being $5 \alpha$-reduced, T can also be aromatized to estradiol (E), which can mediate affective and cognitive behaviors. Proestrous female rats, with high circulating levels of $\mathrm{E}$ as well as androgens, exhibited less anxious behavior relative to diestrous females, with low levels of $\mathrm{E}$, as shown by their increased open arm entries in the elevated plus-maze, longer social interactions, and less freezing time in response to shock (Frye et al., 2000). Estradiol administration to ADX male rats improves memory, as shown by the increased crossover latencies in the inhibitory avoidance task (Frye, 2001). Because T can also be aromatized to $\mathrm{E}$, and $\mathrm{E}$ can alter affective behavior (Frye et al., 2000) and cognitive performance (Farr, Banks, \& Morley, 2000; Frye, 2001), we cannot rule out whether some of the effects of T administration on anxiety and cognitive performance in the present experiment were due to $\mathrm{E}$. In support of the notion that aromatization is not required for these effects, T, DHT, or $3 \alpha$-Diol can produce similar effects on cognitive and affective behaviors, and whereas T can be aromatized to E, DHT or $3 \alpha$-Diol cannot. Hence, the ability of androgens to produce their effects on anxiety and cognitive performance cannot be solely explained by their aromatization to E.

In summary, the present findings provide further evidence for endogenous $\mathrm{T}$ or administration of $\mathrm{T}$ to produce analgesia and anxiolysis and improve cognitive performance. T administration produced analgesia in the tailflick task. Intact rats were more exploratory, spending more time interacting with a conspecific in social interaction, and less fearful, spending less time burying the prod in the defensive burying task. Androgen-replete rats explored the elevated plus-maze more than did the androgen-depleted rats. Intact rats also demonstrated an improvement in cognitive performance in the inhibitory avoidance task relative to androgen-depleted rats, and T-replaced rats showed an even higher improvement in cognitive performance relative to intact and androgen-depleted rats. In light of the clear clinical relevance of these findings, the extent to which these effects of androgens are due to the genomic actions of $\mathrm{T}$ or the nongenomic actions of its metabolite, $3 \alpha$-Diol, will be the subject of ongoing investigation.

\section{REFERENCES}

Astur, R. S., Ortiz, M. L., \& Sutherland, R. J. (1998). A characterization of performance by men and women in a virtual Morris water task: A large and reliable sex difference. Behavioural Brain Research, 93, 185-190.

BARdo, M. T., \& VAlone, M. J. (1994). Morphine-conditioned analgesia using a taste cue dissociation of taste aversion and analgesia. Psychopharmacology, 114, 269-274.

BEATTY, W. W. (1984). Hormonal organization of sex differences in play fighting and spatial behavior. Progress in Brain Research, 61, 315-330.

Bitran, D., Kellogg, C. K., \& Hilvers, R. J. (1993). Treatment with an anabolic-androgenic steroid affects anxiety-related behavior and alters the sensitivity of cortical $\mathrm{GABA}_{\mathrm{A}}$ receptors in the rat. Hormones \& Behavior, 27, 568-583.
Boissy, A., \& Bouissou, M.F. (1994). Effects of androgen treatment on behavioral and physiological responses of heifers to fear-eliciting situations. Hormones \& Behavior, 28, 66-83.

Bradley, D. R., \& Wygant, C. R. (1998). Male and female differences in anxiety about statistics are not reflected in performance. Psychological Reports, 82, 245-246.

BRUDZYNSKI, S. M., \& KROL, S. (1997). Analysis of locomotor activity in the rat: Parallelism index, a new measure of locomotor exploratory pattern. Physiology \& Behavior, 62, 635-642.

Cheeta, S., Irvine, E. E., Kenny, P. J., \& File, S. E. (2001). The dorsal raphe nucleus is a crucial structure mediating nicotine's anxiolytic effects and the development of tolerance and withdrawal responses. Psychopharmacology, 155, 78-85.

Christiansen, K., \& Knussmann, R. (1987). Sex hormones and cognitive functioning in men. Neuropsychobiology, 18, 27-36.

Cunningham, G. R., Tindall, D. J., \& Means, A. R. (1979). Differences in steroid specificity for rat androgen binding protein and the cytoplasmic receptor. Steroids, 33, 261-276.

D' Amour, F. E., \& Sмith, D. L. (1941). A method for determining loss of pain sensation. Journal of Pharmacology \& Experimental Therapeutics, 72, 74-79.

DAVIS, S. (2001). Testosterone deficiency in women. Journal of Reproductive Medicine, 46, 291-296.

DAwson, J. L. (1972). Effects of sex hormones on cognitive style in rats and men. Behavior Genetics, 2, 21-42.

Dunn, R, Copeland, P., Reed, T., \& Frye, C. A. (1998). Anti-anxiety effects of nitric oxide inhibitors. Neuropharmacology, 37, 899904.

FARr, S. A., BANKs, W. A., \& Morley, J. E. (2000). Estradiol potentiates acetylcholine and glutamate-mediated post-trial memory processing in the hippocampus. Brain Research, 864, 263-269.

File, S. E, Pellow, S., \& Braestrup, C. (1985). Effects of the betacarboline, FG 7142, in the social interaction test of anxiety and the holeboard: Correlations between behaviour and plasma concentrations. Pharmacology, Biochemistry \& Behavior, 22, 941-944.

Flood, J. F., Farr, S. A., Kaiser, F. E., La Regina, M., \& Morley, J. E. (1995). Age-related decrease of plasma testosterone in SAMP8 mice: Replacement improves age-related impairment of learning and memory. Physiology \& Behavior, 57, 669-673.

Flood, J. F., Morley, J. E., \& Roberts, E. (1992). Memory-enhancing effects in male mice of pregnenolone and steroids metabolically derived from it. Proceedings of the National Academy of Sciences, 89, 1567-1571.

Forman, L. J., Tingle, V., Estilow, S., \& Cater, J. (1989). The response to analgesia testing is affected by gonadal steroids in the rat. Life Sciences, 45, 447-454.

Frick, K. M., Burlingame,L. A., Arters, J. A., \& Berger-Sweeney,J. (2000). Reference memory, anxiety and estrous cyclicity in C57BL/ 6NIA mice are affected by age and sex. Neuroscience, 95, 293-307.

FrYe, C. A. (1995). Estrus-associated decrements in a water maze task are limited to acquisition. Physiology \& Behavior, 57, 5-14.

FrYe, C. A. (2001). Estradiol tends to improve inhibitory avoidance performance in adrenalectomized male rats and reduces pyknotic cells in the dentate gyrus of adrenalectomized male and female rats. Brain Research, 889, 358-363.

Frye, C. A., \& Duncan, J. E. (1994). Progesterone metabolites, effective at the $\mathrm{GABA}_{\mathrm{A}}$ receptor complex, attenuate pain sensitivity in rats. Brain Research, 643, 194-203.

Frye, C. A., \& Duncan, J. E. (1995). Estradiol benzoate potentiates neuroactive steroids' effects on pain sensitivity. Pharmacology, Biochemistry \& Behavior, 53, 27-32.

Frye, C. A., Duncan, J. E., Basham, M., \& Erskine, M. S. (1996). Behavioral effects of $3 \alpha$-androstanediol. II: Hypothalamic and preoptic area actions via a GABAergic mechanism. Behavioral Brain Research, 79, 119-130.

Frye, C. A., \& LACEY, E. H. (2001). Posttraining androgens' enhancement of cognitive performance is temporally distinct from androgens' increases in affective behavior. Cognitive, Affective, \& Behavioral Neuroscience, 2, 172-182

Frye, C. A., \& McCormick, C. M. (2000). The neurosteroid, $3 \alpha$ - 
androstanediol, prevents inhibitory avoidance deficits and pyknotic cells in the granule layer of the dentate gyrus induced by adrenalectomy in rats. Brain Research, 7, 166-170.

Frye, C. A., McCormick, C. M., Coopersmith, C., \& Erskine, M. S. (1996). Effects of paced and non-paced mating stimulation on plasma progesterone, $3 \alpha$-diol and corticosterone. Psychoneuroendocrinology, 21, 431-439.

Frye, C. A., Park, D., Tanaka, M., Rosellini, R, \& Svare, B. (2001). The testosterone metabolite and neurosteroid $3 \alpha$-androstanediol may mediate the effects of testosterone on conditioned place preference. Psychoneuroendocrinology, 26, 731-750.

Frye, C. A., Petralia, S. M., \& Rhodes, M. E. (2000). Estrous cycle and sex differences in performance on anxiety tasks coincide with increases in hippocampal progesterone and $3 \alpha, 5 \alpha$-THP. Pharmacology, Biochemistry \& Behavior, 67, 1-10.

Frye, C. A., \& ReEd, T. A. (1998). Androgenic neurosteroids: Antiseizure effects in an animal model of epilepsy. Psychoneuroendocrinology, 23, 385-399.

Frye, C. A., Van Keuren, K. R., \& Erskine, M. S. (1996). Behavioral effects of $3 \alpha$-androstanediol. I: Modulation of sexual receptivity and promotion of GABA-stimulated chloride flux. Behavioural Brain Research, 79, 109-118.

Frye, C. A., Van Keuren, K. R., Rao, P. N., \& Erskine, M. S. (1996a). Analgesic effects of the neurosteroid $3 \alpha$-androstanediol. Brain Research, 709, 1-9.

Frye, C. A., Van Keuren, K. R., Rao, P. N., \& Erskine, M. S. (1996b). Progesterone and $3 \alpha$-androstanediol conjugated to bovine serum albumin affects estrous behavior when applied to the MBH and POA. Behavioral Neuroscience, 110, 603-612.

Gallagher, A. M., De Lisi, R., Holst, P. C., McGillicuddy-De Lisi, A. V., Morely, M., \& Cahalan, C. (2000). Gender differences in advanced mathematical problem solving. Journal of Experimental Child Psychology, 75, 165-190.

Gallo, M. A., \& Smith, S. S. (1993). Progesterone withdrawal decreases latency to and increases duration of electrified prod burial: A possible rat model of PMS anxiety. Pharmacology, Biochemistry \& Behavior, 46, 897-904.

Gaulin, S. J. C., \& Fitzgerald, R. W. (1989). Sexual selection for spatial-learning ability. Animal Behaviour, 37, 322-331.

Ge, J., Barnes, N. M., Costall, B., \& Naylor, R. J. (1997). Effect of aversive stimulation on 5-hydroxytryptamine and dopamine metabolism in the rat brain. Pharmacology, Biochemistry \& Behavior, 58, 775-783.

GEE, K. W. (1988). Steroid modulation of the GABA/benzodiazepine receptor-linked chloride ionophore. Molecular Neurobiology, 2, 291317.

Gonzalez, M. I., Farabollini, F., Albonetti, E., \& Wilson, C. A (1994). Interactions between 5-hydroxytryptamine (5-HT) and testosterone in the control of sexual and nonsexual behavior in male and female rats. Pharmacology, Biochemistry \& Behavior, 47, 591601.

Gupta, D., Rager, K., Zarzycki, \& Eichner, M. (1975). Levels of luteinizing hormone, follicle-stimulating hormone, testosterone, and dihydrotestosterone in the circulation of sexually maturing intact male rats and after orchidectomy and experimental bilateral cryptorchidism. Journal of Endocrinology, 66, 183-193.

Holson, R. R., Ali, S. F., Scallet, A. C., Slikker, W., \& Paule, M. G. (1989). Benzodiazepine-like behavioral effects following withdrawal from chronic delta-9-tetrahydrocaanabinol administration in rats. Neurotoxicology, 10, 605-619.

Isgor, C., \& Sengelaub,D. R. (1998). Prenatal gonadal steroids affect spatial behavior, CA1 and CA3 pyramidal cell morphology in rats. Hormones \& Behavior, 34, 183-198.

Janowsky, J. S., Chavez, B., \& Orwoll, E. (2000). Sex steroids modify working memory. Journal of Cognitive Neuroscience, 12, 407-414.

JANOWSKY, J. S., OviatT, S. K., \& ORWOLl, E. S. (1994). Testosterone influences spatial cognition in older men. Behavioral Neuroscience, 108, 325-332.

JoHnson, U. (1997). Coping strategies among long-term injured competitive athletes. A study of 81 men and women in team and individual sports. Scandinavian Journal of Medicine \& Science in Sports, 7, 367372.
Johnston, A. L., \& File, S. E. (1991). Sex differences in animal tests of anxiety. Physiology \& Behavior, 49, 245-250.

Kritzer, M. F., McLaughlin, P. J., Smirlis, T., \& Robinson, J. K. (2001). Gonadectomy impairs T-maze acquisition in adult male rats. Hormones \& Behavior, 39, 167-174.

LAmbadjIEVA, N. D. (1998). Influence of testosterone on some behavioral reactions of male immature rats. Methods \& Findings in Experimental \& Clinical Pharmacology, 20, 673-677.

Linn, M. C., \& Petersen, A. C. (1985). Emergence and characterization of sex differences in spatial ability: a meta-analysis. Child Development, 56, 1479-1498.

Lund, B. C., Bever-Stille, K. A., \& Perry, P. J. (1999). Testosterone and andropause: The feasibility of testosterone replacement therapy in elderly men. Pharmacotherapy, 19, 951-956.

McCarthy, M. M., Felzenberg, E., Robbins, A., Pfaff, D. W., \& SchWARTZ-Giblin, S. (1995). Infusions of diazepam and allopregnanolone into the midbrain central gray facilitate open-field behavior and sexual receptivity in female rats. Hormones \& Behavior, 29 , 279-295.

McCleary, R., \& Zucker, E. L. (1991). Higher trait- and state-anxiety in female law students than male law students. Psychological Reports, 68, 1075-1078.

McGee, M. G. (1979). Human spatial abilities: Psychometric studies and environmental, genetic, hormonal, and neurological influences. Psychological Bulletin, 86, 889-918.

Moger, W. H. (1977). Serum $5 \alpha$-androstane- $3 \alpha, 17 \beta$-diol, androsterone, and testosterone concentrations in the male rat. Influence of age and gonadotropin secretion. Endocrinology, 100, 1027-1032.

Molina, N., Bedran-de-Castro, M. T., \& Bedran-de-Castro, J. C. (1994). Sex-related differences in the analgesic response to the rat tail immersion test. Brazilian Journal of Medical \& Biological Research, 27, 1669-1672.

Morley, J. E. (2000). Andropause, testosterone therapy, and quality of life in aging men. Cleveland Clinic Journal of Medicine, 67, 880-882.

Morley, J. E., Kaiser F. E., Sih, R., Hajuar, R., \& Perry, H. M., III. (1997). Testosterone and frailty. Clinics in Geriatric Medicine, 13, 685-695.

Morley, K. C., \& McGregor, I. S. (2000). (+/-)-3,4-methylenedioxymethamphetamine (MDMA, "Ecstasy") increases social interaction in rats. European Journal of Pharmacology, 408, 41-49.

O'Connell, A., Earley, B., \& Leonard, B. E. (1994). Phencyclidine prevents spatial navigation and passive avoidance deficits in ibotenate lesioned rats. Neuropharmacology, 33, 1095-1101.

Pellow, S., Chopin, P., File, S. E., \& Briley, M. (1985). Validation of open:closed arm entries in an elevated plus-maze as a measure of anxiety in the rat. Journal of Neuroscience Methods, 14, 149-167.

Pellow, S., \& File, S. E. (1986). Anxiolytic and anxiogenic drug effects on exploratory activity in an elevated plus-maze: A novel test of anxiety in the rat. Pharmacology, Biochemistry \& Behavior, 24, 525-529.

Postma, A., Meyer, G., Tuiten, A., van Honk, J., Kessels, R. P., \& ThiJssen, J. (2000). Effects of testosterone administration on selective aspects of object-location memory in healthy young women. Psychoneuroendocrinology, 25, 563-575.

Rodriguez, M., Sosa, J., Hernandez, G., \& Mas, M. (1984). Pineal indols and testosterone affect exploratory activity of male rats. Experientia, 40, 397-398.

Romero, M. T., Cooper, M. L., Komisaruk, B. R. \& Bodnar, R. J. (1988). Gender-specific and gonadectomy-specific effects upon swim analgesia: Role of steroid replacement therapy. Physiology \& Behavior, 44, 257-265.

Roselli, C. E. (1991). Sex differences in androgen receptors and aromatase activity in microdissected regions of the rat brain. Endocrinology, 128, 1310-1315.

Rosellini, R. A., Svare, B. B., Rhodes, M. E., \& Frye, C. A. (2001). The testosterone metabolite and neurosteroid $3 \alpha$-androstanediol may mediate the effects of testosterone on conditioned place preference. Brain Research Reviews, 37, 162-171.

Silverman, I., Kastuk, D., Choi, J., \& Phillips, K. (1999). Testosterone levels and spatial ability in men. Psychoneuroendocrinology, 24, 813-822.

Smythe, J. W., McCormick, C. M., Rochford, J., \& Meaney, M. J. (1994). The interaction between prenatal stress and neonatal handling 
on nociceptive response latencies in male and female rats. Physiology \& Behavior, 55, 971-974.

Sternbach, H. (1998). Age-associated testosterone decline in men: Clinical issues for psychiatry. American Journal of Psychiatry, 155, 1310-1318.

Stewart, J., Skvarenina, A., \& Pottier, J. (1975). Effects of neonatal androgens on open-field behavior and maze learning in the prepubescent and adult rat. Physiology \& Behavior, 14, 291-295.

STUMPF, W., \& SAR, M. (1976). Steroid hormone target sites in the brain: The differential distribution of estrogen, progestin, androgen and glucocorticosteroid. Journal of Steroid Biochemistry, 7, 1163-1170.

Svensson, A. I., Soderpalm, B., \& Engel, J. A. (2000). Gonadectomy enhances shock-induced behavioral inhibition in adult male rats: Implications for impulsive behavior. Pharmacology, Biochemistry \& Behavior, 65, 731-736.

Treit, D. (1985). The inhibitory effect of diazepam on defensive burying: Anxiolytic vs. analgesic effects. Pharmacology, Biochemistry \& Behavior, 22, 47-52.

Treit, D., Pinel, J. P., \& Fibiger, H. C. (1981). Conditioned defensive burying: A new paradigm for the study of anxiolytic agents. Pharmacology, Biochemistry \& Behavior, 15, 619-626.

VANDENHEEDE, M., \& BouISSOU, M. F. (1993). Effect of androgen treatment on fear reactions in ewes. Hormones \& Behavior, 27, 435-448.

VazQuez-Perey ra,F., Rivas-Arancibia, S., Loaeza-Del Castillo, A,
\& SChNEIDER-Rivas, S. (1995). Modulation of short term and long term memory by steroid sexual hormones. Life Sciences, 56, PL255-PL260. Venault, P., Chapouthier, G., de Carvalho, L. P., Simian, J., Morre, M., Dodd, R. H., \& Rossier, J. (1986). Benzodiazpine impairs and beta-carboline enhances performance in learning and memory tasks. Nature, 321, 864-866.

Verhoeven, G., Heyns, W., \& De Moor, P. (1975). Testosterone receptors in the prostate and other tissues. Vitamins \& Hormones, 33, 265-281.

WARREN, S. G., \& JURASKA, J. M. (1997). Spatial and nonspatial learning across the rat estrous cycle. Behavioral Neuroscience, 111, 259-266.

Williams, C. L., Barnett, A., \& Meck, W. H. (1991). Organizational effects of early gonadal secretions on sexual differentiation in spatial memory. Behavioral Neuroscience, 104, 84-97.

Williams, C. L., \& Meck, W. H. (1991). The organizational effects of gonadal steroids on sexually dimorphic spatial ability. Psychoneuroendocrinology, 16, 155-176.

Zangrossi, H., \& File, S. E. (1992). Behavioral consequences in animal tests of anxiety and exploration of exposure to cat odor. Brain Research Bulletin, 29, 381-388.

(Manuscript received July 25, 2001;

revision accepted for publication November 26, 2001.) 